\title{
Compassionate Use of Midostaurin in Myeloid and Lymphoid Neoplasia with FGFR1 Abnormality
}

\author{
Photis Beris ${ }^{1,2}$, Monika Nagy'1, Daniel Robert' ${ }^{1}$ Kaveh Samii ${ }^{1}$, Tom McKee ${ }^{3}$, Jovita Schuler ${ }^{4}$ \\ ${ }^{1}$ Division of Haematology, University Hospital of Geneva, Geneva, Switzerland \\ ${ }^{2}$ Department of Haematology, Unilabs Coppet, Coppet, Switzerland \\ ${ }^{3}$ Department of Pathology, CMU, Geneva, Switzerland \\ ${ }^{4}$ Novartis Pharma Switzerland, Rotkreuz, Switzerland \\ Email: photis.beris@unilabs.com
}

Received 9 August 2014; revised 7 September 2014; accepted 6 October 2014

Copyright (C) 2014 by authors and Scientific Research Publishing Inc.

This work is licensed under the Creative Commons Attribution International License (CC BY). http://creativecommons.org/licenses/by/4.0/

(c) (i) Open Access

\begin{abstract}
Background: Patients with stem cell myeloproliferative disorders have a particularly poor prognosis and limited treatment options, i.e. mainly aggressive chemotherapy or allogeneic stem cell transplantation. In 2004, Chen et al. reported a patient presenting a t(8;13) (p11;q12) cytogenic anomaly who responded positively to treatment with PKC412 (midostaurin), an oral multi-targeted tyrosine kinase inhibitor. Here, we report a second case treated with the above-mentioned drug. Patient: A 71-year-old woman was diagnosed as having chronic myelogenous leukaemia with eosinophilia secondary to $t(8 ; 13)$ with FGFR1 involvement. Due to her age, an allogeneic stem cell transplantation was not possible. Treatment: A treatment combining aggressive chemotherapy and midostaurin was explored. The patient received one cycle of hyper-CVAD chemotherapy followed by maintenance therapy with midostaurin. A relapse occurred after six months, and she was treated with four more cycles of hyper-CVAD chemotherapy. The patient entered a complete clinical, haematological and cytogenetic remission. A maintenance therapy with midostaurin continued for four months until she developed a chemoresistant relapse followed by acute leukaemia. Conclusion: This is the second case of a $t(8 ; 13)$ myeloid and lymphoid neoplasm with FGFR1 abnormalities treated successfully with midostaurin. Midostaurin is administered orally, allows for outpatient care and in this case showed only occasional and minimal side effects. The combination of hyper-CVAD and midostaurin extended survival by 21 months without allogeneic transplantation. This case further supports the possibility of using midostaurin for the treatment of other diseases with FGFR1 dysregulations; however, specific clinical trials are needed to confirm this hypothesis.
\end{abstract}

\section{Keywords}

PKC412, Myeloid and Lymphoid Neoplasms with Eosinophilia and FGFR1 Abnormality, 


\section{Introduction}

WHO has proposed two categories for myeloid neoplasms presenting with eosinophilia: 1) Chronic eosinophilic leukaemia, not otherwise specified (CEL-NOS), and 2) Myeloid and lymphoid neoplasms with eosinophilia and abnormalities of PDGFRA, PDGFRB or of the fibroblast growth factor receptor 1 (FGFR1) [1]. The second group is haematologically and genetically heterogeneous and often presents as myeloproliferative neoplasm (MPN) with eosinophilia or as T lymphoblastic lymphoma with eosinophilia. Most cases are associated with $\mathrm{t}(8 ; 13)$ (p11;q12), $\mathrm{t}(8 ; 9)(\mathrm{p} 11 ; \mathrm{q} 33)$ or $\mathrm{t}(6 ; 8)$ (q27;p11-12) with the fusion gene being ZNF198-FGFR1, CEP110FGFR1 and FGFR1OP1-FGFR1, respectively. However, several questions relating to eosinophils and hypereosinophilia remain open, and the classification remains controversial since not every molecular defect can be linked to an eosinophil malignancy [2]. Therefore, WHO classification also states that all patients with abnormalities in PDGFRA, PDGFRB or FGFR1 genes need further diagnostic evaluation in order to differentiate between CEL, MPN, acute myeloid leukaemia (AML), T-lymphoblastic lymphoma or other malignancies [3] [4].

Myeloid and lymphoid neoplasms with eosinophilia and abnormalities of FGFR1 derive from a pluripotent haematopoietic stem cell. The clonal growth of eosinophils often results from mutated and thus constitutively activated cytokine receptors, such as the FGFR1 tyrosine kinase (TK) gene, and is associated with poor prognosis [5]. Although some TK-inhibitors are efficacious in treating certain hematopoietic malignancies, there is no effective treatment for this specific group of neoplasms. Only one publication described a partial response to midostaurin (PKC412) [6], a TK inhibitor used mainly for AML and mastocytosis [7]. Thus, only aggressive chemotherapy and allogeneic transplantation are used today to treat these patients [8]. Therapies that are less aggressive would be highly beneficial to the patients. This is particularly true for elderly persons and is becoming increasingly important in an ageing population [9].

We describe here the first patient who has survived chronic myeloid leukaemia with eosinophilia and FGFR1 mutation for over 22 months without stem cell transplantation. The sequential administration of hyper-CVAD chemotherapy and midostaurin as maintenance therapy translated in a significant tumour reduction and control of progression.

\section{Case Report}

A 71-year-old woman with no history of infectious disease was admitted to the hospital in January 2009. On physical examination, lymphadenopathy of the cervical, axillary and inguinal lymph nodes was observed, and the patient presented with fever and dyspnoea.

Peripheral blood values were haemoglobin (Hb) 140 g/dL, platelets $204 \times 10^{9} / \mathrm{L}$ and leukocytes $48 \times 10^{9} / \mathrm{L}$, with the following differential count: neutrophils $66.5 \%$, eosinophils $13.5 \%$, lymphocytes $8.5 \%$, monocytes $7 \%$, basophils $0 \%$, metamyelocytes $4.5 \%$; promyelocytes $0 \%$, myelocytes $3.0 \%$, blast cells $0 \%$. Three days later, peripheral blood reflected increasing eosinophilia. Bone marrow was hypercellular to $90 \%-100 \%$ with marked eosinophilia, which is indicative of chronic myeloid leukaemia associated with eosinophilia. A thoracic-abdominal PET/CT scan revealed spreading adenopathies in cervical, axillary, mediastinal, retroperitoneal, mesenteric and inguinal regions. Pathological examination of biopsied tonsils and cervical lymph nodes was consistent with T-cell lymphoma with infiltration of $\mathrm{CD}^{+}, \mathrm{CD}^{+}, \mathrm{CD}^{+}$, $\mathrm{TIA}^{+}$and $\mathrm{CD} 4^{+ \text {(weak) }}$ T-cells. However, karyotyping and FISH analysis established the presence of a $\mathrm{t}(8 ; 13)$ translocation and a breakpoint within the fibroblast growth factor receptor 1 (FGFR1), the receptor tyrosine kinase that is known to be disrupted in myeloproliferative disorders, leading to the final diagnosis of myeloid and lymphoid neoplasia with eosinophilia and FGFR1 abnormality (Figure 1). At this point, T-cell receptor rearrangements analysis by PCR revealed atypical polyclonal T-cell proliferation.

The patient received one complete cycle of hyper-CVAD chemotherapy, which resulted in a very good clinical and haematological response (Hb $110 \mathrm{~g} / \mathrm{L}$, WBC $4.1 \mathrm{~g} / \mathrm{L}$, platelets $140 \mathrm{~g} / \mathrm{L}$ ) leading to a near-normal white blood cell count, the disappearance of eosinophilia and reduced adenopathy. Continuation of chemotherapy was considered as high risk due to the poor physical condition of the patient, and an allogeneic stem cell transplanta- 

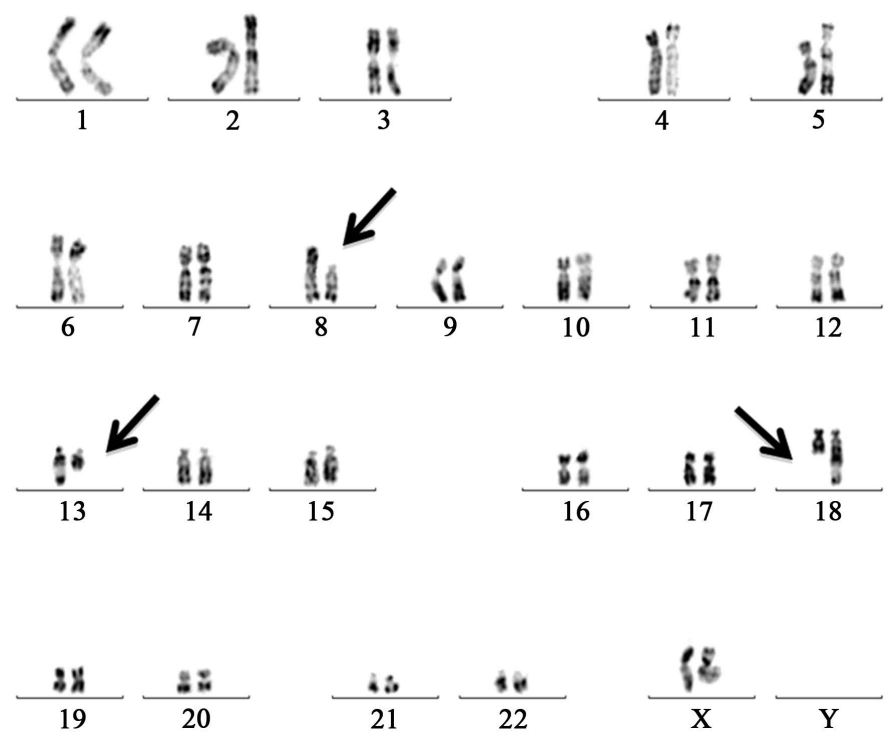

Figure 1. Karyotyping from the bone marrowaspiration. Karyotype and lymph node biopsy confirmed a myeloid and lymphoid neoplasia with a $\mathrm{t}(8 ; 13 ; 18)$ translocation (the arrows indicate the 8 to 13 , the 13 to 18 and 18 to 8 translocation).

tion was ruled out due to age. Thus, the decision was taken to discharge the patient at week six and to put her on midostaurin $100 \mathrm{mg}$ p.o. twice daily, along with prophylactic medication (ciprofloxacin $500 \mathrm{mg}$ daily, fluconazole $400 \mathrm{mg}$ weekly). After four weeks, the patient had a persistently high platelet count $\left(>1000 \times 10^{9} / \mathrm{L}\right)$ and was started on hydroxyurea ( $2 \mathrm{~g}$ daily), which was then reduced to $1 \mathrm{~g}$ daily upon normalisation of the platelet count. The clinical remission was successfully maintained on midostaurin, and the patient enjoyed normal activity and quality of life for six months. Midostaurin was generally well tolerated by the patient, with only occasional nausea and vomiting, which were treated symptomatically.

Six months after starting treatment, the patient relapsed with clinical symptoms of lymphadenopathy and eosinophilia. A PET/CT scan revealed a recurrence of the myeloid neoplasia, and an atypical T-cell proliferation could be confirmed by bone marrow aspiration and lymph node histology (Figure 2). Clonality PCR analysis of the T-cell receptors (TCRs) detected a small monoclonal T-cell population, indicating a clonal development of the initial atypical polyclonal T-cell pathology (Figure 3). Midostaurin was discontinued, and the patient received four of the six planned cycles of hyper-CVAD chemotherapy. During treatment, the patient required a transfusion of red blood cells and platelets. A complete evaluation of the disease showed that the patient was in complete clinical, haematological and cytogenetic remission. A PET/CT scan revealed no active residual tumours. The $\mathrm{Hb}$ improved from 91 to $117 \mathrm{~g} / \mathrm{L}$, the WBC count rose from 2.8 to $14.5 \mathrm{~g} / \mathrm{L}$ and the platelet count increased to $80 \times 10^{9} / \mathrm{L}$. The differential count was: 50\% neutrophils, $9 \%$ eosinophils, $11.5 \%$ monocytes, $20.5 \%$ lymphocytes and $9 \%$ myelocytes. The $t(8 ; 13)$ translocation was no longer detected by FISH, and the karyotype appeared normal. Maintenance treatment with $100 \mathrm{mg}$ midostaurin twice daily was then resumed. Four months later, the patient relapsed, with reappearance of lymphadenopathy (confirmed by lymph node biopsy) and eosinophilia (27\% eosinophilia out of a total WBC of $\left.11.4 \times 10^{9} / \mathrm{L}\right)$.

At this point, the overall condition of the patient did not allow for an additional chemotherapy, and a palliative treatment was given. The patient developed pancytopenia, with the following blood count: WBC $1.3 \times$ $10^{9} / \mathrm{L}$; platelets $27 \times 10^{9} / \mathrm{L}$; and $\mathrm{Hb} 76 \mathrm{~g} / \mathrm{L}$. Bone marrow examinations revealed a massive blastic infiltration of lymphoid and myeloid cells (about 70\%). Cytogenetic studies confirmed a leukemic transformation with the identificationof five different clonal populations (46, XX, t(8;13;18)[3]/47, idem, +21[3]/47, XX, idem, +der(8) $\mathrm{t}(8 ; 13 ; 18)$, mar1[7]/48, idem, $-7,+21,+\operatorname{mar} 1,+\operatorname{mar} 2[6] / 46$, XX[1], expressing, in addition tothe $\mathrm{t}(8 ; 13 ; 18)$ (p11;q12;q23)) with monosomy 7 and trisomy 21, a supplementary chromosome originating from chromosome 8, as well as 2 markers. The patient passed away two months later as a result of pancytopenia secondary to an acute myeloid and lymphoid leukaemia in October 2010 (21 months after diagnosis). 


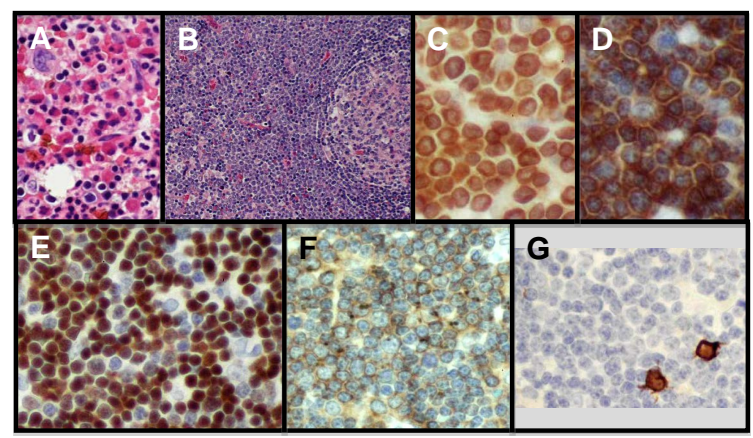

Figure 2. At first presentation of the patient, tonsil and cervical lymph node biopsies revealed infiltrations of $\mathrm{CD}^{+}, \mathrm{CD}^{+}, \mathrm{CD}^{+}$, $\mathrm{Tia}^{+}$and CD4 weakly positive T-cells, which strongly suggested peripheral T-cell lymphoma. Panel A represents the bone marrow aspiration showing hypercellularity. Panel B shows the eosinophilic infiltration of the lymph nodes. Panel C \& D represent the CD3 \& CD2 infiltration, respectively. Panel E represents the CD5 ${ }^{+}$ cells infiltration, panel $\mathrm{F}$ the weakly CD4 positive cells and panel $\mathrm{G}$, negative CD20 cells.

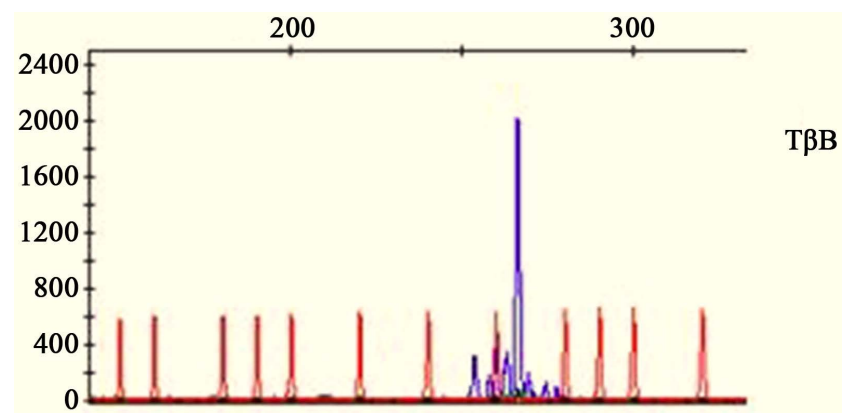

Figure 3. The figure shows electrophoresis trace for the analysis of the lymphomatous component of the tumour. The size markers are shown in red with a quantitative scale in base pairs noted above. The y axis shows a quantification of the fluorescent intensity. The clonal peak from the patients sample is shown in blue.

\section{Discussion}

The classification of the myeloid and lymphoid neoplasia with FGFR1 abnormality is still subjected to some controversy. However, ten different translocations have been described in the neoplasms involving abnormal expression of FGFR1, each of which results in the fusion of a distinct protein partner to the C-terminal FGFR1 [10] [11]. The most frequently described protein partner, as in the case presented here, is ZMYM2-FGFR1 (formerly known as ZNF198-FGFR1) [11]. The clinical features of this disorder can vary: some patients present with lymphoma with mainly lymph node involvement, while others present myeloproliferative features, such as splenomegaly [3] [4]. Systemic symptoms such as fever, weight loss and night sweats are often present. The prognosis is extremely poor, and allogeneic stem cell transplantations remain the only option for achieving long-term remission [1] [10]. However, in an elderly patient like the case presented here, a transplantation is not an option. Other strategies must be developed in order to maintain quality of life, reach remission or achieve a cure. In our case, we trusted that a TK inhibitor such as midostaurin, known to induce only occasional adverse effects and already used in the field of haematology, could potentially have a positive effect on the overall quality of life when combined with an aggressive chemotherapy [6] [12]. An initial success with midostaurin was noted in 2004 in a patient with progressive leucocytosis, lymphadenopathy and splenomegaly associated with $\mathrm{t}(8 ; 13)(\mathrm{p} 11 ; \mathrm{q} 12)$ myeloproliferative disorder [6]. This patient experienced an improvement in leucocytosis and lymphadenopathy, with mitigation of the symptoms; however, cytogenetic abnormality persisted, suggesting the need for additional therapies to also reach cytogenetic remission. Our strategy thus consisted of combining two 
therapies: an aggressive hyper-CVAD therapy followed by a midostaurin maintenance therapy. A first cycle of hyper-CVAD therapy resulted in a very good clinical and haematological response, allowing the patient to be discharged under midostaurin maintenance therapy. A relapse occurred six months later, likely due to the progression from an atypical polyclonal T-cell proliferation to a clonal expansion of the atypical T-cells. Despite the development of the disease, complete clinical, haematological and cytogenetic remission could be achieved after four cycles of hyper-CVAD therapy. The midostaurin maintenance regime was restored; however, acute leukaemia developed after an additional four months and palliative care was chosen.

This case illustrates the possibility of reaching partial to complete remission without stem cell transplantation while maintaining quality of life. Keeping in mind that the dosage, time of treatment and combination with an aggressive chemotherapy might not have been optimal, it illustrates the great potential of such combined treatment. Currently, midostaurin (PKC412), which is a broad-range multi-kinase inhibitor, is under clinical development for the treatment of acute myeloid leukaemia (AML, in sequential combination with standard chemotherapy) and aggressive systemic mastocytosis (ASM, as a single agent monotherapy). Midostaurin principally inhibits protein kinase $\mathrm{C}$, with sub-micromolar $\mathrm{IC}_{50}$ s for each of the main subtypes [13] [14]. Other proteins inhibited by midostaurin include: FGFR-3, 3K560 [15], VEGF receptor-2 [13], PDGF-R FLT3 [16] and c-Kit [13]. It also inhibits the ZMYM2-FGFR1 fusion kinase, which has been implicated in myeloproliferative syndrome with $t(8 ; 13)$ association. The in vivo efficacy of midostaurin was demonstrated in two murine bone marrow transplant models of ZNF198-FGFR3-induced myeloproliferative syndrome. Mice treated with the drug had significantly extended survival compared to control mice treated with a placebo [6].

\section{Conclusion}

In conclusion, we report a case of a rare, recently described disease with an extremely poor prognosis. Considering that these myeloid and lymphoid neoplasms are the result of ZMYM2-FGFR1 fusion, the use of a tyrosin kinase inhibitor such as midostaurin is justified. Our case illustrates clearly that this drug is more effective when combined with aggressive chemotherapy and may be considered as a maintenance treatment after induction of a very good remission. Unfortunately, the rarity of the disease makes it very difficult to conduct any kind of clinical studies aimed at determining the best therapeutic scheme of chemotherapy combined with midostaurin.

\section{Acknowledgements}

We thank Dr. Francine Mugneret, Centre Hospitalier Universitaire Dijon, Laboratoire de Cytogénétique, Dijon, France, for performing cytogenetic studies and a FISH analysis. We are also thankful to Dr. Zoriana Salamanczuk, Laboratoire de Cytogénétique Hématologique, Centre Médical Universitaire, Geneva, Switzerland, for her participation in the cytogenetic tests. Manuscript preparation was supported by SAN GmbH, Reiden, Switzerland. Novartis Pharma Schweiz AG provided the drug free of charge and covered publication-related expenses.

\section{References}

[1] Bain, B.J. (2010) Myeloid and Lymphoid Neoplasms with Eosinophilia and Abnormalities of PDGFRA, PDGFRB or FGFR1. Haematologica, 95, 696-698. http://dx.doi.org/10.3324/haematol.2009.021675

[2] Valent, P., Horny, H.P., Bochner, B.S., Haferlach, T. and Reiter, A. (2012) Controversies and Open Questions in the Definitions and Classification of the Hypereosinophilic Syndromes and Eosinophilic Leukemias. Seminars in Hematology, 49, 171-181. http://dx.doi.org/10.1053/j.seminhematol.2012.01.009

[3] Bain, B.J., Gilliland, D.G., Vardiman, J.W. and Horny, H.P. (2008) Chronic Eosinophilic Leukemia, Not Otherwise Specified. In: Swerdlow, S.H.C., Campo, E., Harris, N.L., et al., Eds., World Health Organization (WHO) Classification of Tumours, IARC Press, Lyon, 51-53.

[4] Bain, B.J., Gilliland, D.G., Vardiman, J.W. and Horny, H.P. (2008) Myeloid and Lymphoid Neoplasms with Eosinophilia and Abnormalities of PDGFRA, PDGFRB or FGFR1. In: Swerdlow, S.H.C., Campo, E., Harris, N.L., et al., Eds., World Health Organization (WHO) Classification of Tumours, IARC Press, Lyon, 51-53.

[5] Macdonald, D., Aguiar, R.C., Mason, P.J., Goldman, J.M. and Cross, N.C. (1995) A New Myeloproliferative Disorder Associated with Chromosomal Translocations Involving 8p11: A Review. Leukemia, 9, 1628-1630.

[6] Chen, J., Deangelo, D.J., Kutok, J.L., Williams, I.R., Lee, B.H., Wadleigh, M., Duclos, N., Cohen, S., Adelsperger, J., Okabe, R., Coburn, A., Galinsky, I., Huntly, B., Cohen, P.S., Meyer, T., Fabbro, D., Roesel, J., Banerji, L., Griffin, J.D., Xiao, S., Fletcher, J.A., Stone, R.M. and Gilliland, D.G. (2004) PKC412 Inhibits the Zinc Finger 198-Fibroblast 
Growth Factor Receptor 1 Fusion Tyrosine Kinase and Is Active in Treatment of Stem Cell Myeloproliferative Disorder. Proceedings of the National Academy of Sciences, 101, 14479-14484. http://dx.doi.org/10.1073/pnas.0404438101

[7] Hatzimichael, E., Georgiou, G., Benetatos, L. and Briasoulis, E. (2013) Gene Mutations and Molecularly Targeted Therapies in Acute Myeloid Leukemia. American Journal of Blood Research, 3, 29-51.

[8] Savage, N., George, T.I. and Gotlib, J. (2013) Myeloid Neoplasms Associated with Eosinophilia and Rearrangement of PDGFRA, PDGFRB, and FGFR1: A Review. International Journal of Laboratory Hematology, 35, 491-500.

[9] Erba, H.P. (2010) Has There Been Progress in the Treatment of Older Patients with Acute Myeloid Leukemia? Best Practice Research Clinical Haematology, 23, 495-501. http://dx.doi.org/10.1016/j.beha.2010.09.012

[10] Jackson, C.C., Medeiros, L.J. and Miranda, R.N. (2010) 8p11 Myeloproliferative Syndrome: A Review. Human Pathology, 41, 461-476. http://dx.doi.org/10.1016/j.humpath.2009.11.003

[11] Valent, P., Gleich, G.J., Reiter, A., Roufosse, F., Weller, P.F., Hellmann, A., Metzgeroth, G., Leiferman, K.M., Arock, M., Sotlar, K., Butterfield, J.H., Cerny-Reiterer, S., Mayerhofer, M., Vandenberghe, P., Haferlach, T., Bochner, B.S., Gotlib, J., Horny, H.P., Simon, H.U. and Klion, A.D. (2012) Pathogenesis and Classification of Eosinophil Disorders: A Review of Recent Developments in the Field. Expert Review of Hematology, 5, 157-176. http://dx.doi.org/10.1586/ehm.11.81

[12] Gotlib, J., Berube, C., Growney, J.D., Chen, C.C., George, T.I., Williams, C., Kajiguchi, T., Ruan, J., Lilleberg, S.L., Durocher, J.A., Lichy, J.H., Wang, Y., Cohen, P.S., Arber, D.A., Heinrich, M.C., Neckers, L., Galli, S.J., Gilliland, D.G. and Coutre, S.E. (2005) Activity of the Tyrosine Kinase Inhibitor PKC412 in a Patient with Mast Cell Leukemia with the D816V KIT Mutation. Blood, 106, 2865-2870. http://dx.doi.org/10.1182/blood-2005-04-1568

[13] Fabbro, D., Ruetz, S., Bodis, S., Pruschy, M., Csermak, K., Man, A., Campochiaro, P., Wood, J., O’Reilly, T. and Meyer, T. (2000) PKC412-A Protein Kinase Inhibitor with a Broad Therapeutic Potential. Anti-Cancer Drug Design, 15, 17-28.

[14] Marte, B.M., Meyer, T., Stabel, S., Standke, G.J., Jaken, S., Fabbro, D. and Hynes, N.E. (1994) Protein Kinase C and Mammary Cell Differentiation: Involvement of Protein Kinase C Alpha in the Induction of Beta-Casein Expression. Cell Growth Differentiation, 5, 239-247.

[15] Growney, J.D., Clark, J.J., Adelsperger, J., Stone, R., Fabbro, D., Griffin, J.D. and Gilliland, D.G. (2005) Activation Mutations of Human c-KIT Resistant to Imatinib Mesylate Are Sensitive to the Tyrosine Kinase Inhibitor PKC412. Blood, 106, 721-724. http://dx.doi.org/10.1182/blood-2004-12-4617

[16] Weisberg, E., Boulton, C., Kelly, L.M., Manley, P., Fabbro, D., Meyer, T., Gilliland, D.G. and Griffin, J.D. (2002) Inhibition of Mutant FLT3 Receptors in Leukemia Cells by the Small Molecule Tyrosine Kinase Inhibitor PKC412. Cancer Cell, 1, 433-443. http://dx.doi.org/10.1016/S1535-6108(02)00069-7 
Scientific Research Publishing (SCIRP) is one of the largest Open Access journal publishers. It is currently publishing more than 200 open access, online, peer-reviewed journals covering a wide range of academic disciplines. SCIRP serves the worldwide academic communities and contributes to the progress and application of science with its publication.

Other selected journals from SCIRP are listed as below. Submit your manuscript to us via either submit@scirp.org or Online Submission Portal.
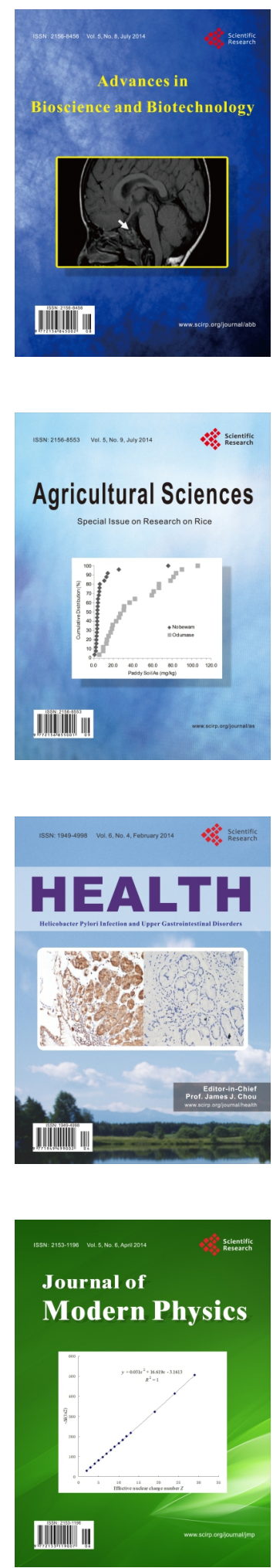
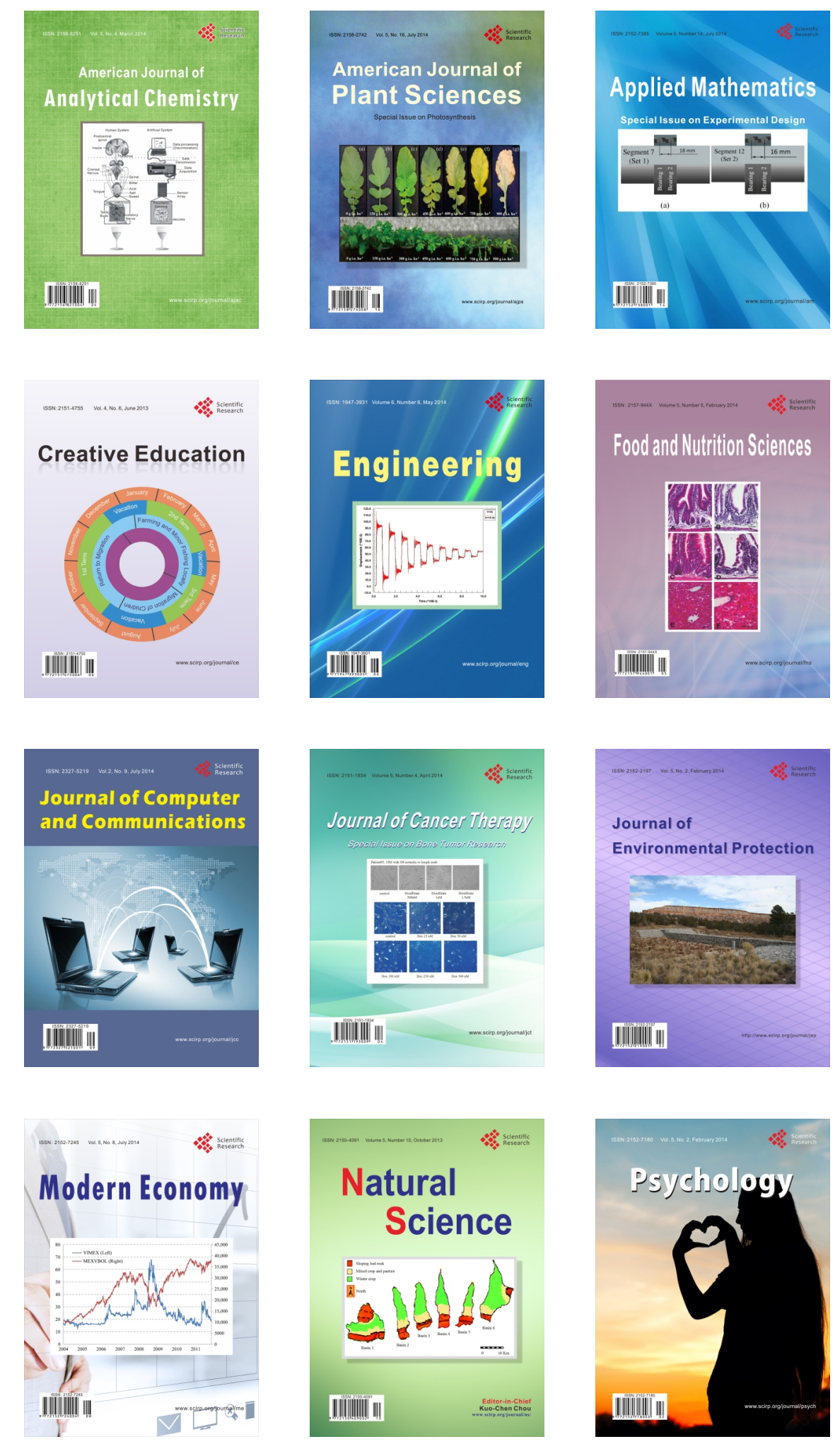